\title{
Oversewing and the Problem of Book Preservation in the Research Library
}

\begin{abstract}
Oversewing, the principal method employed by the commercial bindery, is considered in relation to the problem of book preservation in the research library, along with other methods which the writer believes to be conducive to book preservation. The economic forces that have led to the decline of binding standards, the inadequacy of such standards in terms of the research library, and the responsibility of both librarians and binders in the quest for effective means of book preservation are considered.
\end{abstract}

I

N HIS delightful and informative book, The Enemies of Books, William Blades writes of binders, "Oh, the havoc I have seen committed by binders! You may assume your most impressive aspect-you may write down your instructions as if you were making out your last will and testament-you may swear you will not pay if your books are ploughed-'tis all in vain; the creed of the binder is very short, and comprised in a single article, and the article is the one vile word 'Shavings.'"

One of the methods employed in binding and rebinding books and periodicals for the academic library has concerned the writer for some time, and has prompted this paper. This particular method may be described by the vile word "Oversewing"; and this one word seems to be the substance of the modern commercial binder's creed-a baleful creed, in truth, and one that should deeply concern all academic librarians.

The preservation of books is a matter of vital importance to the research li-

${ }^{1}$ William Blades, The Enemies of Books (Chicago: A. C. McClurg, 1880), pp. 30-31.

Mr. Roberts is Chief, Circulation Department, John M. Olin Library, Washington University. brary. While it is true that information retrieval systems and the numerous types of microforms may make it easier to obtain information and require less storage space in the library, in many areas of scholarship there is still no adequate substitute for the printed book. The reader with book in hand enjoys a physical and intellectual freedom that no retrieval system or microviewer can give him.

The primary purposes of this paper are to describe the basic method used by the commercial bindery in binding and rebinding materials, ${ }^{2}$ to point out the disadvantages of this method, and to suggest other, superior methods of binding and why it is imperative that academic librarians unite in an effort to implement these methods. In addition, an attempt will be made to explain the economic conditions that have led to the present-day crisis in binding, and the role of librarians and binders in alleviating this crisis.

\section{Binding Methods}

Joining Sections. Of all the many steps involved in binding and rebinding, per-

\footnotetext{
2The expression "commercial bindery" is used so as to distinguish between machine binding and binding done largely or exclusively by hand.
} 
haps the most important and least understood is the method employed in "joining" sections or leaves. ${ }^{3}$ While there are numerous methods of joining, ${ }^{4}$ oversewing, perfect binding, and the several forms of flexible sewing are the ones usually employed by craft and commercial binderies, and will be our concern here. Two of these, oversewing and perfect binding, are similar in that the sections are reduced to individual leaves by cutting or planing the back of the book. Flexible sewing, on the other hand, retains the original sections and, consequently, preserves the original structure of the book. On that basis alone it is inherently superior to either of the other methods. It cannot be overemphasized that once a book has been oversewn or perfect-bound, its basic structure is permanently altered. A book sewn on cords may be taken apart and sewn on tapes, if need be, and vice versa. The trouble and expense would be considerable, no doubt, but it could be done. But a perfect-bound or oversewn book cannot be taken apart and sewn on tapes or cords, or, in all likelihood, rebound again in any manner.

Oversewing. Oversewing is the principal method employed by commercial binderies in sewing the greatest number of books at the lowest possible price. The oversewing process entails removal of the old backstrip, glue and sewing. This usually is accomplished by removing the covers and planing or grinding down the back of the book. The leaves are then gathered together and given a very light coat of glue. A number of leaves about two millimeters thick is then positioned in the oversewing machine and sewn by a process that drives

\footnotetext{
${ }^{3}$ Alexander J. Vaughan, Modern Bookbinding (London: Charles Skilton, 1960), p. 24.

4See, e.g., Manley Banister, Pictorial Manual of Book-Binding (New York: Ronald Press, 1958), pp. 6-9, 17, 25; Jeff Clements, Bookbinding (London: Arco, 1963), pp. 58-61; and Hellmut LehmannHaupt, ed., Bookbinding in America: Three Essays (Portland, Maine: Southworth-Anthoenses Press, 1941), pp. 145-58.
}

heavy cords obliquely into the paper. The cords coming in from over and underneath interlock and, in turn, are interlaced by smaller threads at right angles. A second group of leaves is then placed above the first and the process is repeated. The first and final few groups of leaves are sewn several times in order to impart added strength to the front and back of the book. The final result is a book with sewing of enormous strength and tightness, and little flexibility.

The shortcomings of oversewing, while few in number, are decisive:

1. An oversewn book does not open easily and will not lie flat. ${ }^{5}$

2. Oversewing presumes the destruction of the original sections, thus making further rebinding all but impossible.

3. The oversewn book has a greatly diminished inner margin. Aside from the obvious loss of proportion, lessening the inner margin may result in damage to, or partial concealment of, plates and illustrations.

4. A book that is tightly sewn and has little inner margin is difficult to photocopy and is frequently damaged in the attempt.

5. Paper that is even a little brittle will break due to the unyielding grip of oversewing.

Perfect Binding-The Minor Alternative. Perfect binding, which was developed after years of trial and error, is a misnomer of the first order. It is not true binding at all, and is most assuredly not perfect. The book is first prepared for binding by removing the old backstrip and sewing, if any existed. The leaves are then gathered together evenly and clamped into position. The book is

\footnotetext{
5 This is an inconvenience to the reader and, consequently, a book that does not open easily may be forced open and one that does not lie flat may be bent back in an effort to improve its flexibility. This can do irreparable damage to a book, and, indeed, may be singled out as a leading cause of the destruction of innumerable oversewn books.
} 
then ready for the machine. The leaves are warped to one side, a warm plastic adhesive is applied, and, finally, the back is covered with a heavy mull, or backstrip. The book is then cased. Warping allows the plastic to penetrate between the leaves, the greater the warp the greater the penetration. Perfect binding does have several advantages, most of which are relative to some other form of joining:

1. A perfect-bound book opens easily and lies flat.

2. Soft, spongy paper and relatively old, brittle paper are adaptable to perfect binding.

3. Perfect binding does not cause the removal of as much inner margin as oversewing.

4. It is one of the least expensive forms of rebinding.

It also has some notable disadvantages:

1. It is not as strong as either oversewing or flexible sewing.

2. Perfect binding reduces the inner margin.

3. A perfect-bound book is difficult to rebind again.

4. There is no proof that perfect binding is permanent.

In many cases perfect binding can be an adequate alternative to oversewing. It is best suited for inexpensive books, including some paperbacks, books printed on soft, spongy paper, and, finally, books with slightly brittle paper, which are not of sufficient worth to warrant more expensive binding.

Flexible Sewing-The Major Alternative. Flexible sewing is known to have existed as early as the tenth century, and "was the foundation on which fine binding was built and developed during the next thousand years." ${ }^{\prime \prime}$ In this paper

- Bernard Middleton, A History of English Craft Bookbinding Technique (London: Hafner, 1963), p. 15 . we have used "flexible sewing" as a generic term, and, historically, this is incorrect. Flexible sewing means specifically sewing on raised bands (or cords) ${ }^{7}$ Over the years other methods of sewing were developed in response to different needs, including the flat spine and hollow back, partly for decorative purposes, and, even hundreds of years ago, the need for an "economical" binding. ${ }^{8}$ Among these methods were sewing on raised tapes (or, simply sewing on tapes), and sewing on sawnin cords. Thus, in the honorable craft of book binding, sewing implies the use of tapes or cords, and flexible sewing refers to a particular form. But in our time, and for our consideration, with oversewing and the like to contend with, it is convenient to refer to all sewing on tapes and cords as flexible sewing.

Sewing on Tapes. It is impossible here to describe in any detail the technique of flexible sewing; therefore the descriptions of sewing on tapes and cords given herein are intended only to illustrate the basic nature of the processes, and are not not to be taken as lessons in sewing. Excellent descriptions of hand sewing are to be found in Clements, ${ }^{9}$ Town, ${ }^{10}$ and Vaughan. ${ }^{11}$

The book is first taken apart and prepared for rebinding. The sections are then gathered, knocked up square at the head, and marked for tape positions and kettle-stitch grooves, or kerfs, as they are sometimes called. ${ }^{12}$ Grooves are then sawn into the sections at the kettle-stitch markings. ${ }^{13}$ The sections are then sewn to the tapes, with the sewing thread following the fold (gutter) of the section and emerging at each tape so as to pass behind it. The several tech-

\footnotetext{
" Laurence Town, Book Binding by Hand (2d ed. London: Faber and Faber, 1963), p. 102.

${ }^{8}$ Middleton, op. cit., pp. 17-18.

Op. cit., pp. 33-38.

10 Op. cit., pp. $95-123$.

${ }^{11}$ Op. cit., pp. 24-33.

12 Town, op. cit., p. 98.

13 Sometimes grooves are also made at the tape locations.
} 
niques of flexible sewing are well illustrated in Vaughan. ${ }^{14}$

Sewing on Sawn-In Cords. Sewing on sawn-in cords is similar to sewing on tapes, the principal difference being that heavy cords, which lie in grooves "sawn-in" the folded edges of the sections, are used in place of tapes. Cord sewing is easier and faster than tape sewing because the needle need not puncture the paper or traverse a tape. Its lesser difficulty, however, is overbalanced by the slightly better flexibility and considerably greater strength of tape sewing.

Sewing on Raised Cords-Flexible Sewing. True flexible sewing differs from sewing on tapes and sawn-in cords in that the cords are raised above the sections and rest against them, and the sewing thread is looped completely around the cords, instead of merely passing behind them. Flexible sewing may be done on single or double cords, the former being more flexible, whereas the latter is more durable.

A book sewn on raised cords does not have the flexibility of one sewn on tapes or sawn-in cords, despite the name given the sewing, but it is much stronger. The difference in flexibility stems from the fact that raised cord books have solid backs, whereas books sewn by either of the other methods have hollow backs, which, in conjunction with the looser type of sewing, permits more throw-up in the spine, thus allowing the book to open more easily. ${ }^{15}$ Sewing on double raised cords actually approaches even oversewing in strength, and generally exceeds it in flexibility. Genuine flexible sewing, however, is far too expensive to be considered in rebinding general stack books. This is unfortunate, for no greater tribute may be paid any book than to sew it on raised cords.

Because the cost of raised cord sewing is prohibitive, the substitute methods of

14 Op. cit., p. 31.

${ }^{15}$ Middleton, op. cit., p. 19. sewing on tapes and sawn-in cords must be our immediate concern. Both methods are far superior to perfect binding, and infinitely preferable to oversewing. Their advantages are numerous and impressive:

1. A book sewn on tapes or cords opens easily and lies flat.

2. The sewing is strong and durable.

3. Since most of the strain is carried by the cords or tapes, there is much less danger of the paper breaking. This is very important in the rebinding of books with brittle paper.

4. The sections are preserved, thus retaining the full inner margin of the book.

5. Because the cords or tapes can be continued beyond the limits of the book proper, and extended between boards and board paper, the book is less likely to lose its covers.

6 . In the event a second rebinding becomes necessary, it is easily accomplished, because the book is not at all diminished by the first rebinding.

The single disadvantage of sewing on tapes or sawn-in cords is the relatively high initial cost.

Summary of Joining Methods. The only advantage oversewing has over any other form of joining is low cost, and a library that has a collection of permanent value will find even that advantage to be of dubious merit. While it cannot be denied that the initial cost of oversewing is considerably less than that of flexible sewing, the library that really believes it is saving money by permitting its books to be oversewn simply fails to see the problem in what Hawthorne called the calmly terrible light of logic. Oversewing is strong-very, very strong -and, in fact, in the long run its great strength becomes its greatest weakness. There are but few papers that can withstand the unyielding grip of oversewing over a great number of years, and none of them is economical enough to con- 
sider seriously. The typical oversewn book is so tight and inflexible that simply opening it must eventually cause the paper to break. Once that happens there is no alternative but to replace the book, because a second rebinding would be difficult, if not impossible.

To temper the stinging retorts of irate binders at this point, it would be well to mention the few situations in which oversewing does have some place in the research library. Theses and other materials not made up in folded sections do not lend themselves to many other forms of binding. In addition, a library that must provide multiple copies for one purpose or another might consider oversewing as a temporary means of preservation, the theory being that the duplicates will be used intensively for a time and then discarded. Flexible sewing is too expensive to be considered for multiple copies. On the other hand, the first copy, the one the library will keep permanently, is surely worthy of something better than oversewing.

\section{The State of Binding Today}

Unfortunately, today, to a great extent, books are accorded careless treatment. They are poorly made in the beginning, handled indifferently, and miserably rebound. The responsibility for such treatment lies directly and inescapably with publishers, librarians, and binders. It is not the purpose of this paper to delve into the responsibility of publishers; that would require a lengthy paper in itself. Our concern here is with binders, who are the executioners of the book, and librarians (or, more accurately, university budget determiners) who, knowingly or unknowingly, pass final judgment resulting in that execution. Before venturing into the question of responsibility, however, we must understand clearly what the current binding practices are, why they are that way, and how they may be improved. A convenient place to begin is with the com- mercial bindery, and the economic forces that direct it.

The modern commercial bindery is a product both of the high-speed printing press and of the rising costs of labor. Although machine binding dates well back into the past century, ${ }^{16}$ it was not until the advent of cheap paper and the power-driven press that binding took a sharp turn downward. The power-driven press unleashed a flood of books into the market, and, in conjunction with rising labor costs, compelled the binder to seek more and more sophisticated machinery for binding books. Had his customers been willing or able to pay the price for hand binding, the machine might not have made such inroads into the craft, but apparently they were not; and in any event, the rise of machine binding was to a certain extent unavoidable. It was an inevitable part of that series of industrial revolutions that have been both the blessing and curse of mankind.

Competing in a free market, the commercial binder must charge the lowest possible price for his services in keeping with acceptable business practices. In order to do this, he must bind books in sufficient numbers to assure efficient utilization of his plant, capital equipment, and labor force. Since labor is unquestionably the highest priced of the factors of production, binders have been forced to develop (or copy) binding machinery of ever increasing efficiency. By investing heavily in guillotines, oversewing machines, hydraulic presses, and the like, the binder is able to reduce his labor costs to the point where he can charge a competitive price and still realize a fair profit. Other binders, too, must obey the immutable laws of competition, install high-speed binding equipment, and so bring their own prices into line. Competition, as we can readily see, is much like a seething vortex, bringing into existence faster and

\footnotetext{
${ }^{10}$ Lehmann-Haupt, ed., op. cit., pp. 145-58.
} 
more efficient machinery, resulting in lower and lower prices, with less and less emphasis on hand craftsmanship. Eventually the hand binder is priced out of the industry-at that point it can no longer be called a trade-and he must either seek employment in a bindery specializing in high quality work in relatively small quantities, or give up his profession.

These are substantially the circumstances that have brought about the binding situation existing today. And who can say it is all the binder's fault? Within his own frame of reference, and within the limits imposed upon him by others, mechanization is entirely defensible. The binder cannot be expected to stand alone and watch his business wither away solely in the service of an ideal. The use of an oversewing machine, for example, which is the fastest and most deleterious method of sewing a book, may not be entirely to the liking of the owner of a binding establishment, but, as long as his customers must pay (or insist on paying) minimal prices for their binding, or as long as they are indifferent to-or ignorant of-the irretrievable damage being done their books, the binder has no alternative but to submit to economic forces that are largely beyond his control, and employ laborsaving devices. No, the binder, while by no means entirely blameless, is more an accessory after the fact in the evil process of oversewing.

\section{STANDARDS}

The question fundamental to this discussion is whether or not the standards imposed on the commercial binder are adequate to insure the preservation of books in the research library. They may well be adequate for the public library, the school library, or the special library. But are they adequate for the research library? There is mounting evidence that they are not. The ruling philosophy of the research library is, or should be, that a book is acquired with the intention of retaining it forever. In the over-all sense, there is no such thing as a worthless book in the research library. Whether or not, in fact, they are retained permanently does not detract from the philosophy of permanence. This being the case, it becomes obvious that the binding standards for a research library must be oriented towards preservation in the long run. Proper binding alone cannot guarantee preservation, ${ }^{17}$ but it can and should be of a quality that will enable it to preserve the book as long as possible.

\section{RESPONSIBILITY}

Proper care and preservation of books is of vital importance if the academic library is to continue as the principal preserver of man's accumulated knowledge. The unhappy day may come when the book is no longer essential; but that day is not now, nor is it in the foreseeable future. The truly maddening thing about the inadequacy of book preservation today is that the methods of effective preservation are known and have been known for centuries. What, then, stands in the way? Is it simply the low cost of oversewing as opposed to the relatively high cost of sewing on tapes? Is it the error of attempting to fit the requirements of one type of library to another type of library? Is it that the craft of bookbinding is so far along the road to oblivion that not enough craftsmen can be found who are able or willing to bind books properly, and that the present binding situation will persist until a satisfactory flexible sewing machine is designed? Let us examine each of these possibilities.

Sewing on tapes costs more than over-

${ }^{17}$ The writer is not unaware of the sad fact tha the paper used in book production over the past on hundred years is hardly capable of lasting fifty years much less forever. The paper situation seems to be improving. It is to be hoped that binding standard will improve concurrently. 
sewing, that is true; but it would seem that its undeniable superiority would warrant the added cost. A university that can afford to lavish tens of thousands on a pet project can surely afford to spend as much to preserve its book collection. If money is the only barrier, let it be remembered that we are not alone in this; the scholars of a millennium will praise us or condemn us for what we do now. Judgment, to be sure, must be exercised, for not' every book is worth sewing on tapes. But, where possible, all are worthy of something better than the guillotine and subsequent oversewing.

Were the superiority of flexible sewing slight, or even only moderately great, one might understand its neglect; but the difference literally is between preservation and destruction. The decision should be between perfect binding and flexible sewing, and not between oversewing and nothing. An interesting analogy in this matter of cost can be drawn between superior binding and automated systems in libraries. When a particular automated system is proposed, it is usually pointed out that it can do more for the library than the old system, or that it can do better the things the old system was capable of doing. Seldom is it denied that the new system will cost more; it should cost more if it has more to offer. Why cannot the same argument be applied in the matter of binding? Flexibile sewing costs more, but it has more to offer: a great deal more. It offers the preservation of the book collection!

The present binding standards seem more applicable to those libraries that do not have, and have no intention of maintaining, historical collections. A library that discards old editions in favor of new editions, that does not intend to keep more than say five years of a periodical title, or that weeds its collection of uncirculated books is in no way simi- lar to the research library-academic or public. The binding requirements of the two are entirely different and their standards should and must be different.

It is sometimes said that even if librarians were able to pay for superior binding, the commercial binderies would not be willing to make the shift from machine to hand sewing. This is sheer nonsense. Providing they are able to realize a fair return on their investment, there is no reason why binders would be unwilling to cooperate. It would take time to amortize the percentage of machines that would no longer be needed, but this represents no insurmountable problem. It is also said that even if the money were available, not enough craftsmen could be found to meet the demand. Barring an over-all shortage of manpower, this simply is not true. A fairly long period of apprenticeship would be required to turn out the necessary journeymen, but the labor market is not so inflexible that workers could not be attracted in sufficient numbers, providing money was really available to allow charges for binding that would include a fair wage and just profit. Unfortunately, this "fair wage" would probably be so high as to make hand binding impractical, if not impossible. The crux of the matter, as always, is money. It can be spent for this, or it can be spent for that, but apparently it cannot be spent for both. So be it.

Assuming both money and manpower to be in short supply, and therefore hand binding out of the question, could a workable machine be designed that would sew books on tapes? ${ }^{18}$ A machine does exist that can sew on tapes, but it is limited in usefulness by being more or less restricted to a very narrow range of book sizes. The number of tapes on which a book must be sewn varies di-

\footnotetext{
${ }^{18}$ This is now under study. See Gladys T. Piez, "Library Technology and RTSD-Goals in Common," Library Resources and Technical Services, X (Winter $1966), 16$.
} 
rectly with the length of the book. A volume five or six inches high may be sewn on two tapes (although three would be better), but one eight, ten, or twelve inches high must be sewn on three, four, or five tapes. What is needed is a machine that can sew a variety of book sizes on a varying number of tapes.

Fortunately, a number of responsible librarians are aware and do care about the problem of book preservation.
But the interest of many more librarians is needed. Awareness is essential to progress, and those who do not know must learn. The binders cannot be expected to initiate the necessary changes, and it would be unfair to expect it of them. If enough librarians demand high standards of binding, eventually the money will be made available, the machines will be designed, and then, perhaps, there may still be hope for the book.

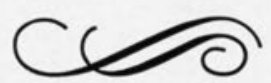

